Peer-Reviewed Article

ISSN: 2162-3104 Print/ ISSN: 2166-3750 Online

Volume 7, Issue 3 (2017), pp. 841-855

(C) Journal of International Students

http://jistudents.org/

doi: 10.5281/zenodo. 570037

\title{
International Student Teaching: A Transformational Experience
}

\author{
Ricardo González-Carriedo \\ University of North Texas, USA \\ Jesús López de Nava \\ Denton Independent School District, USA \\ Manuel Salas Martínez \\ University of Seville, Spain
}

\begin{abstract}
Today, being a teacher requires understanding and positively responding to the cultural and linguistic nuances present in the classroom. The increasingly diverse schools are placing higher expectations on teachers in regard to the use of multicultural practices. This is compelling teacher preparation programs to find new formulas to adequately train teacher candidates. International student teaching programs have been shown to yield important benefits for participants. This article describe an international student teacher exchange program between the University of North Texas and the University of Seville (Spain) and reflects on the effects of the experience on a Spanish preservice teacher and his mentor teacher in Texas. Implications and suggestions for teaching preparation programs are also provided.
\end{abstract}

Keywords: Constructivism, culturally responsive teaching, cross-cultural practices, interculturalism, international student teaching, situated learning

Teachers are the most important factor in the success of children's learning in school (e.g. Cochran-Smith \& Zeichner, 2005; Hannaway \& Mittleman, 2011). Also, students in schools today are more diverse than ever in regard to race, ethnicity, linguistic, religious, socio-economic, and cultural backgrounds (de Jong, 2011). Consequently, schools are placing higher expectations on teachers in regard to their multicultural practices. These expectations are also present on teacher preparation programs across the nation. 
A relatively new trend related to teacher preparation programs is the development of international programs where teacher candidates have the option of conducting their practical experience in another country. This article describes the experiences of the participants in an international student teacher exchange program in the spring of 2015. The program is the result of an agreement between the University of North Texas and the University of Seville, in Spain. Since its inception, in 2012, the two universities exchange five student teachers each school year for a period of five weeks, typically between the months of January and May. Students from both institutions are given the opportunity to participate in the program after a rigorous selection process that includes an application, a review of the students' transcripts, and an interview. The American students are placed by the University of Seville at a bilingual K-12 charter school in Seville, Spain. Concurrently, the Spanish students are placed by the University of North Texas at several bilingual public schools within the Denton Independent School District. In both cases, the students collaborate with one or more mentor teachers. In their role as student teachers, most of this time is spent teaching in the classroom. The hosting universities provide logistical support as well as ongoing feedback through classroom observations and regular meetings.

This article is a reflection of the experience from the point of view of one of the Spanish student teachers participating in the program and his mentor teacher at the elementary school in north Texas where the student teaching took place. Their roles as student teacher and mentor teacher allowed them to gain a broad perspective of the impact of an international student teacher program. The observations in the classroom and the school are rendered in this article as a description through an open-ended narrative. As participant-observers of the experience, the co-authors accept that the narrative has a degree of subjectivity (Angrosino, 2005).

Consequently, we will first describe the experiences of the student teacher and the impact that the program had on him as he worked with the first grade students and the mentor teacher. Then, we will present the perspective of the mentor teacher, including the effect that mentoring an international student teacher had on his students. We will finish with a discussion and implications for teacher preparation programs. Since both the student teacher and the mentor teacher are co-authoring this article, real names are used.

\section{LITERATURE REVIEW}

This study is framed under the assumption that cognition is situated and learning is heavily influenced by the location or situation where a person learns (Brown, Collins, \& Duguid, 1989; Putnam \& Borko, 2000; Smith \& Semin, 2007). In other words, situated learning "emphasizes the idea that 
much of what is learned is specific to the situation in which it is learned" (Anderson, Reder, \& Simon, 1996). Under this epistemological stance, the environment plays a fundamental role in the learning experience and defines how knowledge is created (Ticknor, 2012).

Today, it is widely accepted that effective teaching requires an understanding of the cultural nuances present in the classroom, an understanding that may require engagement in field experiences beyond the traditional context of the teacher preparation programs (Lupi \& Batey, 2009). In these programs, teacher candidates typically learn about teaching in university classrooms and engage in a teaching practicum at a local school. However, this traditional model of teacher training leaves most preservice teachers with limited intercultural experiences (Cushner \& Mahon, 2002).

International experiences, on the other hand, provide participants with an exposure to diverse cultures and backgrounds. International programs specially designed for teachers "emerged as an important way to expand the worldview of new teachers and bring a needed global perspective to their curriculum development and classroom instruction" (Stachowski \& Sparks, 2007, p. 116). This has the potential to enrich and broaden their personal development (Lupy \& Batey, 2009; McCartney \& Harris, 2014) as well as shaping culturally responsive teachers. Moreover, the effects of international experiences in regard to the global perspectives gained by the participants tend to be long-lasting (Batey \& Lupi, 2012) and result in an increased desire to consider multiple perspectives and incorporate cross-cultural perspectives in the classroom (Doppen \& An, 2014).

Previous studies of the effects of international experiences on teachers have shown the value of these cross-cultural practices (WillardHolt, 2001), including "professional and personal changes, such as an increased confidence, a better appreciation and respect for differences of others and other cultures" (Pence \& Macgillivray, 2008, p. 14). A direct contact with intercultural experiences produces an enhanced sensitivity to and awareness of issues related to the cultural and linguistic backgrounds of the students (Alfaro, 2008; Bryan \& Sprague, 1997).

Extensive research has shown that teaching practices are influenced by the experiences and perspectives teachers bring to the classroom (e.g. Brookhart \& Freeman, 1992; Goodman, 1988; Pajares, 1992; Renzaglia, Hutchins, \& Lee, 1997). Cushner (2007) explained that in the case of international student teaching experiences, the impact is multifaceted. First, student teachers learn about themselves and others. Second, they grow in self-confidence and efficacy. Finally, student teachers experience an increased global mindedness, intercultural sensitivity and awareness of domestic diversity. 
The relatively extensive literature in the area of international student teaching has not so far incorporated the voices of the student teachers or their mentors in schools. This study aims at filling this gap in the literature, providing a narrative of the significance of an international student teaching program as perceived by a student teacher and a mentor teacher. The reflections contained in this paper will serve to inform teacher education programs about the potential of international exchanges of pre-service teachers.

\section{School Setting}

\section{CONTEXT OF THE PROGRAM}

The five student teachers sent by the University of Seville to the United States were placed by the Denton Independent School District in three different schools. This article focuses on one of the student teachers, placed at Lee Elementary. As of the school year 2013-2014, this school had 573 students. Of these, 66 percent were Hispanic, 23 percent White, and eight percent African American. Seventy-eight percent of the students were economically disadvantaged and 46 percent were classified as English Language Learners.

\section{Participants}

Manuel was part of a group of five student teachers from the University of Seville, in Spain, who travelled to the United States in the spring of 2015. Concurrently, five American student teachers travelled to Seville. Both groups were to complete a four-week exchange. This was the third year in which the universities exchanged students.

As a teacher candidate, Manuel has spent the last four years in the teacher preparation program at the University of Seville. Previously, he had studied for three years at a normal school, specializing in elementary education. He perceives education as the cornerstone of society and views the role of teachers as enablers of the personal and academic development of all students. For him, education is the tool to achieve a more fair and humane society.

Manuel's mentor teacher in this international student teaching program was Jesús, a teacher with six years of experience in the classroom. He has taught in one- and two-way dual-language programs. As a mentor teacher, his role was to model for the student teacher the best instructional practices and explain the reasoning behind them. As a native of Mexico, Jesús was able to effectively communicate with Manuel in Spanish.

\section{Student Teaching in the United States}

Manuel described his experience as a student teacher in the United States as vastly enriching, both personally and professionally. As a fourth- 
year student at the University of Seville, in Spain, he was highly motivated to embark on a student teaching program where he could gain hands-on experience in the classroom. His student teaching had two phases. First, he spent ten weeks at a school in Spain teaching first grade mathematics. During that time, he also worked in the design of cross-curricular thematic units. The most recent education reform in Spain requires teachers to depart from the traditional linear teaching based on a textbook and instead work collaborately across subjects. After a one week intermission, he traveled to Texas, where he conducted four additional weeks of student teaching. The proximity of both experiences allowed him to observe the contrasts between both schools but also to note some similarities.

Some of the features of the American school that caught Manuel's attention were the pedagogical paradigms under which teachers worked, the school organization, the status of teachers, and access to the teaching profession. These disparities between his former experiences in education, both as a student and a teacher candidate, and his new environment pressed him to re-examine his own beliefs about education. In this process, he found himself constantly pondering what ideas and practices could be transferred from one system to the other. For example, Manuel appreciated the emphasis on reading and mathematics that students in the Texas school received from the early grades. He was also appreciative of the socioconstructivist approach used in the classrooms, based on collaboration and interaction among the students. However, Manuel quickly became aware of certain systemic elements lacking in the American school, mostly related to the status of educators. Whereas in Spain most teachers are civil servants employed for life, in the United States teachers have one-year contracts and job security is dependent upon factors such as student enrollment and annual reviews. Also, in Manuel's opinion teachers in Spain are more autonomous in regard to instructional matters. In his view, teachers in the United States are much more tied in regard to what to teach (state and district standards) and when to teach it (scope and sequence). He also saw a high degree of bureaucratization in American schools.

One of the first things that Manuel observed after his arrival to the United States was that teachers were not obligated to follow a textbook. In fact, teachers were encouraged to find their own resources to support students' learning. This allowed them to tailor their lesson plans to the needs of their specific students, using a wide array of materials and resources to teach different topics. In one class, for example, Manuel's mentor teacher used flash cards to teach his second grade students, all of whom were English language learners, about marine animals. At the same time, the students used a SmartBoard to interact with materials related to the oceans and life in the water. They accessed photographs, videos, and games related to this topic. In a Spanish school, Manuel would have seen the teacher and 
students working with the textbook.

Another feature of the American school that intrigued Manuel was the role of the school's administration. In Spain, principals are considered pedagogical leaders and provide instructional support to teachers. They are also the representiaves of teachers in the relationships with the public administration. Manuel was surprised by the power of principals in the United States to hire teachers, a power that is reserved to the department of education in Spain. In his country, access to teaching depends on a competitive examination where students must demonstrate their theoretical and practical knowledge of education. These exams are typically extremely challenging and only a small percentage of candidates gain access to openings at the schools.

A third element that fascinated Manuel was the quantity and variety of resources available at the American school, both in regard to staff and materials. Among the first, he observed that children with special needs had certified staff specifically trained to serve them. He also remarked about the work of reading specialists in the classrooms. Other resources that greatly impacted Manuel were the availability of children's literature in every classroom, the school library, the science laboratory, and the technological tools at the disposal of teachers. All of this clearly surpassed the resources typically available in a Spanish school.

A fourth aspect of Manuel's experience was his exposure to a bilingual program. The school where he student taught implements a oneway dual-language program, a type of bilingual education characterized by the balanced use of English and Spanish in school. In one-way programs, all students in the classroom are classified as English language learners. Following the Gómez and Gómez model, students in first grade receive instruction in mathematics through the English language. Language arts, science and social studies are taught in Spanish. Starting in $2^{\text {nd }}$ grade, language arts is taught in both English and Spanish (López Estrada, Gómez, \& Ruiz-Escalante, 2009). The program aims at fully developing the bilingual and biliterate skills of the students.

One element that Manuel thought was missing from the American school was what he termed a democractic education. For him, this term encompassed the creation of a curriculum based on dialogue with the students (and not imposed by the authorities in a top-down approach), the use of diverse sources of information in the classroom, the organization of students in assemblies where they have a chance to voice their concerns, and the analysis of social problems related to the school's contexts. The importance of democratic education was stressed by Manuel when he reflected on his overall student teaching experience:

The two schools where I have student taught, in Spain and the 
United States, serve mostly economically disadvantaged students. Students from both schools have similar characteristics, such as low socio-economic status families, immigrant students, students experiecing a cultural mismatch between their home culture and the mainstream culture, and the lack of an overall plan in society to alleviate social inequalities.

Manuel also found the school culture to be substantially different than anything that he had experienced in Spain. The daily pledge of allegiance at the beginning of the day, the national anthem before school events, and the emphasis on standardized testing were elements that surprised him greatly. The latter differed significantly from what he had experienced in Spain, where there is currently a public debate on the adequacy of implementing standardized tests in schools. The Spanish government's attempt to put into effect these tests has found considerable opposition from teachers, parents and students. In contrast, Manuel was stunned by the importance that the state exam, the State of Texas Assessment of Academic Readiness (STAAR) had. Teachers changed their routines and focused for several weeks on preparing their students for a battery of state and district tests.

Especially interesting for Manuel was the change in pedagogical paradigms that he experienced during his student teaching at the American school. He observed that in the United States there is a considerable emphasis on teachers collaborating with other teachers, planning their lessons together, and sharing resources and materials. Students are also encouraged to work collaborately with other peers. This constructivist approach based on experiencing and investigating is in stark contrast with the approach used in Spain, where most information is extracted from the textbooks and the teacher.

Manuel's perception of the role of schools in society was also strengthened by his participation in the international exchange, as the following excerpt indicates:

Schools have the responsibility of ensuring the success of all students, catering to the diverse needs of their students and constructing a curriculum based on dialogue. For this, teachers need to take advantage of the cultural capital students bring to the classroom and use it as a bridge toward the notion of social justice.

In conclusion, Manuel gained a new perspective on education as a consequence of his international experience in the United States. For him, the inter-connectedness of today's world makes international experiences not just desirable but needed. 


\section{Mentoring an International Student Teacher}

From the mentor teachers' perspective, the presence of an international student teacher in the classroom had clear advantages. However, there were also some challenges that had to be overcome, such as the adaptation of the student teacher to the school. The support of the mentor teacher in this period was fundamental to the success of the experience. This support included exposing Manuel to new pedagogical approaches, some of which involved the use of technology. At the end, Jesús' view of the experience was that Manuel's stay at an American school will have long-lasting effects, both personal and professional.

\section{Benefits}

Meeting the needs of English language learners is a fascinating albeit challenging task. The range of their English language proficiency and their previous schooling experiences is such that instruction needs to be tailored almost at the individual level. In consequence, even when the classroom size is relatively small, teachers find it difficult to provide the one-on-one support that the students require.

Jesús, the mentor teacher, used the term blessing to describe the presence of Manuel in the classroom. The students benefited from having a second teacher working with them. This allowed Jesús to spend more time with students who had difficulties keeping pace with the class, knowing that at the same time the rest of the students were also being provided support. Also, students in the classroom were exposed to Manuel's teaching style. Some students may be able to understand a concept better when that concept is presented in different formats. The instructional techniques that Manuel brought to the classroom served to complement those of Jesus. Another benefit of the presence of a student teacher in the classroom was that the motivation of the students clearly swelled. Students in the early grades immensely enjoy having an extra teacher in the room, especially when the student teacher comes in mid-year. Students get excited and are eager to demonstrate to the student teacher all they have learned. Lastly, having Manuel in the classroom allowed Jesús to implement some of the models of co-teaching that he had been exposed to during his training as a teacher candidate and during the in-service professional development sessions provided by the school district.

Less tangible but equally important was the influence that Manuel had on the second grade students, most of whom had little awareness of places or cultures outside of their own. It was clear from the moment when Jesús introduced Manuel in class that the students were curious about him. Using a projector, Jesús displayed a world map on the screen so that students could see where Spain was located as well as the distance that Manuel had to travel to come to their school. All children were excited to 
know that Manuel had come from such a distant place. The excitement grew as Manuel pointed out other places in Europe that he had visited. When Jesús asked him how he had managed to communicate with the locals in all those countries, Manuel responded that English was the language of choice for travelers. This was probably the first time in their six or seven years of life that these children realized that English, the language that they were learning, was used not only in Texas, but also in many other parts of the world. They also realized that many people in the world beyond the borders of the United States were trying to learn English, just like them.

This influence was also present in regard to the use of the students' first language, Spanish. Students quickly came to the conclusion that the variety of Spanish that Manuel used was somehow different from their own variety. Jesús' dialect of the Spanish language, Mexican-Spanish, matched the students' but Manuel's was typical of the language of the southern Spanish region of Andalusia. The variation was not significant enough to prevent communication but was sufficient to cause one of the students in class raise her hand and, referring to Spaniards, say "I had heard that they talk funny." This made both the teacher and the student teacher share a glance and smile, as both realized that the student was serious about her remark. Interestingly, being exposed to Manuel's Spanish influenced not only the students' views about the world and languages in general but also their own use of Spanish. One expression commonly used by Spaniards is vale, the English equivalent of $\mathrm{OK}$. They heard the word vale so many times from Manuel that students began to use it in class. This showed Jesús that his students were really paying attention to Manuel's way of speaking.

For Jesús, there is no doubt that the knowledge, skills, and hands-on experience gained in the United States will positively impact Manuel's teaching career in Spain. Combining what he learned from his experience student teaching abroad with the training at his home university, he will be able to implement excellent teaching practices that will benefit his students in the environment where they live, grow, and develop. He will also be able to share what he learned in the United States with his colleagues and administrators in Spain. This will open the door for other teachers to be exposed to new ideas about teaching and learning, potentially benefiting many more students.

At a personal level, being exposed to different cultures is always a life changing event. Manuel is now more likely to value and embrace diversity. According to Jesús, all teacher candidates should have the opportunity to engage in an international experience.

\section{Adaptation and Support}

One of the main concerns of this international student teaching program is its short term nature. A long period of adaption could leave little 
time for the student teachers to assume teaching responsibilities. However, Manuel seemed to adapt quickly to the dynamics of Jesús' class, understanding the classroom procedures and becoming an integral part of the daily routines. This was accomplished by encouraging the student teacher to follow a scaffolding model based on observing, questioning, collaborating, and co-teaching.

This acclimatization had some challenges. One of the major surprises that Manuel had was the fact that Jesús did not use a textbook, as is always the case in Spain. In Jesús' school, the goal is for students to be able to explore, discover, collaborate, think critically, and problem solve. Therefore, teachers are constantly finding, creating, and developing new resources as they design their lesson plans. For lesson delivery, teachers use the gradual release model (Fisher \& Frey, 2003), starting with a whole-class mini lesson, followed by guided instruction, collaboration between bilingual pairs, and independent practice. This pedagogical model was new to Manuel.

Likewise, the instructional setting in the classroom was another element of surprise for Manuel. Students in Spain are usually seated in rows and separated from each other. In Texas, he encountered a seating arrangement that is suitable for collaboration. Tables are used instead of desks and, where tables are not available, desks are grouped together. This has the effect of promoting conversation, discussion, and cooperation among the students.

To support Manuel and help him with his period of adaptation, Jesús asked him to observe an entire day of instruction and take detailed notes, including questions for the teacher. As that day progressed, Jesús checked at regular intervals with Manuel to explain the rationale behind his instructional activities. At the end of the day, after students had left, Jesús and Manuel sat and spent a considerable amount of time engaged in a dialogue about the day's experiences. During this dialogue, Manuel asked any questions he still had, giving Jesús a chance to further explain his actions in the classroom. Later in the day Manuel wrote his reflections in a journal, a practice that he kept for the duration of his stay in Texas. This journal gave Manuel an opportunity to pause and think about his experiences at the school. He reflected about the instructional strategies he observed in the classroom, how students responded to different activities, and his perceptions about the school. The journal, in sum, provided him with a space to express his hopes and concerns about teaching.

As Manuel was feeling more and more comfortable, Jesús started to ask him to put what he had learned into practice. In this way, Manuel began working with the students and assuming greater responsibilities in the classroom. Both Manuel and the students thrived and, while the first learned 
about new teaching techniques and strategies, the latter learned language and content.

\section{New Pedagogical Approaches}

Literacy is one of the critical components of Jesús' second grade classroom. As part of a dual-language program, the goal is for students to become not only bilingual but also biliterate in English and Spanish. To meet this goal, the school uses balanced literacy (Pressley, Roehring, Bogner, Raphael, \& Dolezal, 2002) as a model for teaching, reading, and writing. Under this model, specific blocks of time are allocated within the instructional schedule, allowing students to engage in reading and writing workshops. Manuel had the chance to observe and then facilitate these workshops. First, the teacher reads a story out loud. Next, the class moves to shared reading where the teacher reads to the class but the students assist and complement the reading. Then, guided reading follows, reversing the roles and having students read while the teacher assists and complements. Finally, independent reading takes place, allowing students to apply their reading skills and interact with the text without the teacher's intervention. This instructional model was new to Manuel but he quickly understood and embraced it.

Another instructional element that Manuel was excited about was the use of technology in the classroom. Jesús used an interactive projector $\left(\right.$ Smart Board ${ }^{\circledR}$ ) and software (Smart Notebook ${ }^{\circledR}$ ) to deliver all of his instruction in all content areas. This allowed his students to interact with his lessons, going to the screen and using their fingers to draw, write, and drag objects, physically manipulating the concepts that they were learning about. The level of engagement is extremely high and all students are always eager to participate. This powerful instructional tool is quickly mastered by the students, allowing them to learn and practice academic concepts independently and collaboratively through the use of teacher created mathematics, science, and reading interactive activities.

Also in connection to the use of technology, Manuel was able to see first-hand how Jesús' students used classroom computers and iPad tablets as tools for research and final product presentation, among other applications. Making these devices available for students is essential as we support them as globally competitive twenty-first century learners.

\section{IMPLICATIONS}

Manuel's participation in a student teaching program in the United States was a transformational experience. The personal and professional growth that he experienced confirms previous studies that point to the potential of international programs to enrich and broaden participants' views of the world (Cushner \& Mahon, 2002; Lupi \& Batey, 2009; Pence \& 
Macgillivray, 2008). Specifically, the inter-cultural experience gave Manuel an opportunity to reflect on the concept of education as a whole as well as on the different elements present in the schools, both in Spain and the United States. Field experiences and reflection are critical elements of any teacher preparation program (Acquah \& Commins, 2013). The international component added to the depth and meaning of both elements. Students in general, and student teachers in particular, need to be given opportunities for self-examination and participation in cross-cultural experiences (Brown, 2004). We believe that the international student teacher exchange program described in this article accomplished this.

Also significant was that Manuel's view of education as the promoter of change in society was reinforced after his stay in north Texas, where he had the opportunity to observe a student-centered pedagogy. For example, he noted that teachers (1) adapted their instructional strategies to the diverse needs of their students, (2) used students' previous knowledge and experiences as a bridge to teach new concepts, and (3) incorporated multicultural elements matching their students' cultural backgrounds.

From Jesús' perspective, Manuel's presence in the classroom might have served as a reminder that the world is not a static reality but rather a place continually transformed (Freire, 1970/2000). This transformation is not only a consequence of the changing social context of schools but also of the change in the students themselves. The increasing presence of students traditionally labeled as minorities in schools should serve as a reminder to educators that the end purpose of education is to achieve greater social justice (F. Javier Murillo Torrecilla, personal communication, February 20, 2015). In his role of mentor teacher, Jesús modeled practices aimed at helping elementary students "to think critically about subject matter, doctrines, the learning process itself, and their society" (Short, 1993, p. 25). He was able to accomplish this by using a problem-posing and problem solving approach where students were given a high degree of autonomy in their own learning. The use of bilingual pairs where students collaborate and work together toward a common goal is an example of the socioconstructivist approach used by Jesús.

For the elementary students, having an international student teacher in the classroom was an invaluable opportunity to broaden their awareness of the world. Meeting individuals from another country is a life-lasting experience (Batey \& Lupi, 2012). However, in spite of their differing origins, the elementary students and the student teacher shared two very important traits. Not only was Spanish their first language but also both Manuel and the students were English learners. The linguistic and cultural connection that was formed was so strong that students continued to ask about him weeks after Manuel's departure. 


\section{CONCLUSION AND SUGGESTIONS}

The perceptions and experiences collected in this article substantiate previous studies describing how international student teacher programs contribute to forming global-minded and culturally aware teachers. Participants in these programs consistently report personal and professional growth. The exposure to a different language, culture, and school context provides student teachers with an enhanced understanding of the needs of students, especially those with a culturally or linguistically diverse background.

Manuel's visit to the United States had important implications for the elementary students, the mentor teacher, and himself. For the students, his presence in the classroom raised awareness about the cultural and linguistic diversity that exists in the world. Also, they were exposed to a different set of instructional techniques and strategies. For the mentor teacher, working with Manuel gave him an opportunity to reflect on his own teaching practices and the best ways to serve his students. Manuel was exposed to an educational system, which, in many aspects, departs from what he learned as a teaching candidate in Spain, making his time in the United States an invaluable experience with potentially far-reaching effects on this professional career. For example, he observed how teachers in Texas collaborated creating lesson plans and sharing resources for their classrooms. The constructivist approach he observed contrasts with the traditional approach of most Spanish classrooms, where the textbook is the centerpiece of instruction. Manuel reflected on these differing pedagogical approaches and expressed a desire to adopt student-centered strategies in his future career in Spain, collaborating with other teachers and individualizing instruction to meet the needs of all students.

International student teacher exchange programs have obvious benefits, as the program between the University of North Texas and the University of Seville has shown. In the case of our program, we have learned that the timing of the student teaching is important. Manuel's visit took place at the very end of the school year, when teachers were in the process of administering end-of-year assessments, a lengthy process that takes away from the normal academic routine. An earlier time when instructional time is not diverted to standardized testing would be more appropriate. Also, student teachers would benefit the most if they spent time with more than one teacher. A rotating model where they spend one week with a teacher would expose them to a variety of mentor teachers and student groups, making the experience more valuable. It is our hope to see in the near future an increase in the number of teacher education programs in the United States participating in international student teacher exchange programs. This would undoubtedly enrich our classrooms. 


\section{REFERENCES}

Acquah, E. O., \& Commins, N. L. (2013). Pre-service teachers' beliefs and knowledge about multiculturalism. European Journal of Teacher Education, 36(4), 445-463. doi:10.1080/02619768.2013.787593

Alfaro, C. (2008). Global student teaching experiences: Stories bridging cultural and intercultural difference. Multicultural Education, 15(4), 20-26.

Anderson, J. R., Reder, L. M., \& Simon, H. A. (1996). Situated learning and education. Educational Researcher, 25(4), 5-11.

Angrosino, M. V. (2005). Recontextualizing observation: Ethnography, pedagogy, and the prospects for a progressive political agenda. In N. K. Denzin, \& Y. S. Lincoln, The SAGE handbook of qualitative research (3rd ed.) (pp. 729745). Thousand Oaks, CA: Sage Publications.

Batey, J., \& Lupi, M. (2012). Reflections on student interns' cultural awareness developed through a short-term international internship. Teacher Education Quarterly, 39(3), 25-44.

Brookhart, S. M., \& Freeman, D. J. (1992). Characteristics of entering teacher candidates. Review of Educational Research, 62, 37-60.

Brown, E. (2004). What precipitates change in cultural diversity awareness during a multicultural course: The message of the method? Journal of Teacher Education, 55, 325-340.

Brown, J. S., Collins, A., \& Duguid, P. (1989). Situated cognition and the culture of learning. Educational Researcher, 18(1), 32-42.

Bryan, S. L., \& Sprague, M. M. (1997). The effect of overseas internships of early teaching experiences. The Clearing House, 70(4), 199-201.

Cochran-Smith, M., \& Zeichner, K. M. (2005). Studying teacher education: The report of the AERA panel on research and teacher education. Mahwah, NJ: Lawrence Erlbaum Associates.

Cushner, K. (2007). The role of experience in the making of internationally-minded teachers. Teacher Education Quarterly, 34(1), 27-39.

Cushner, K., \& Mahon, J. (2002). Overseas Student Teaching: Affecting Personal, Professional, and Global Competencies in an Age of Globalization. Journal of Studies in International Education, 6(1), 44-58.

de Jong, E. J. (2011). Foundations for multilingualism in education. Philadelphia, PA: Caslon.

Doppen, F., \& An, J. (2014). Student teaching abroad: Enhancing global awareness. International Education, 43(2), 59-75.

Fisher, D., \& Frey, N. (2003). Writing instruction for struggling adolescent readers: A gradual release model. Journal of Adolescent \& Adult Literacy, 46(5), 396-405.

Freire, P. (1970/2000). Pedagogy of the oppressed. New York: Continuum.

Goodman, J. (1988). Constructing a practical philosophy of teaching: A study of teacher candidates' perspectives. Teacher and Teacher Education, 4(2), 121-137.

Hannaway, J., \& Mittleman, J. (2011). Education politics and policy in a era of evidence. In D. Mitchell, R. Crowson, \& D. Shipps, Shaping education policy (pp. 81-91). New York: Routledge.

López Estrada, V., Gómez, L., \& Ruiz-Escalante, J. A. (2009). Let's Make Dual Language the Norm. Educational Leadership, 66(7), 54-58. 
Lupi, M., \& Batey, J. (2009). Teaching interships: Creating successful transformational experiences. SRATE Journal, 18(2), 48-55.

McCartney, H., \& Harris, T. (2014). The image of the child constructed and transformed by preservice teachers in international contexts. Action in Teacher Education, 36(4), 264282.

Pajares, M. F. (1992). Teachers' beliefs and educational research: Cleaning up a messy construct. Review of Educational Research, 62(3), 307-332.

Pence, H., \& Macgillivray, I. (2008). The impact of an international field experience on preservice teachers. Teaching and Teacher Education, 24(1), 14-25.

Pressley, M., Roehring, A., Bogner, K., Raphael, L. M., \& Dolezal, S. (2002). Balanced literacy instruction. Focus on Exceptional Children, 34(5), 1-14.

Putnam, R., \& Borko, H. (2000). What do new views of knowledge and thinking have to say about research on teacher learning? Educational Researcher, 29(1), 4-15.

Renzaglia, A., Hutchins, M., \& Lee, S. (1997). The impact of teacher education on the beliefs, attitudes, and dispositions of preservice special educators. Teacher Education and Special Education, 4, 360-377.

Short, I. (1993). Education is politics. Paulo Freire's critical pedagogy. In P. McLaren, \& P. Leonard, Paulo Freire. A critical encounter (pp. 25-35). London, U.K.: Routledge.

Smith, E. R., \& Semin, G. R. (2007). Situated Social Cognition. Current directions in Psychological Science, 16(3), 132-135.

Stachowski, L. L., \& Sparks, T. (2007). Thirty years and 2.000 student teachers later: An overseas student teaching project that is popular, successful, and replicable. Teacher Education Quarterly, 115-132.

Ticknor, C. S. (2012). Situated learning in an abstract algebra classroom. Educational Studies in Mathematics, 307-323. doi:0.1007/s10649-012

Willard-Holt, C. (2001). The impact of a short-term international expericne for preservice teachers. Teaching and Teacher Education, 17(4), 505-517.

RICARDO GONZÁLEZ-CARRIEDO, $\mathrm{PhD}$, is an assistant professor of bilingual and ESL education at the University of North Texas. His research interests include bilingualism and biliteracy, confluence of immigration and education, and the effects of international experiences on teacher candidates. Email: Ricardo.Gonzalez@unt.edu.

JESÚS LÓPEZ DE NAVA is a first grade bilingual teacher in the Denton Independent School District. He has taught in one-way and two-way dual-language programs for seven years. Email: jlopezdenava@dentonisd.org

MANUEL SALAS MARTÍNEZ is a teacher candidate at the University of Seville, Spain. His area of certification is elementary education. E-mail: manuelsalas1989@hotmail.es 